\title{
Results of Surgical Treatment of Advanced Gastric Cancer. Case Series with Follow-Up
}

\author{
Resultados del Tratamiento Quirúrgico del Cáncer Gástrico Avanzado. \\ Serie de Casos con Seguimiento
}

Carlos Manterola ${ }^{1,2} \&$ Nataniel Claros $^{3}$

MANTEROLA, C. \& CLAROS, N. Results of surgical treatment of advanced gastric cancer. Case series with follow-up. Int. J. Morphol., 38(5):1479-1484, 2020.

SUMMARY: Gastric cancer (CG) is the second leading cause of cancer deaths. The best treatment option for patients with advanced GC (AGC) is still surgery, which involves performing a gastrectomy and D2 lymphadenectomy (D2L). The aim of this study was to determine postoperative morbidity (POM) and 5-year OS in patients resected by AGC without neoadjuvant. Case series with follow-up of patients with AGC undergoing total or subtotal gastrectomies and D2L, consecutively at RedSalud Mayor Temuco Clinic, between 2008 and 2019. The outcome variables were POM and 5-year OS. Other variables of interest were surgical time, number of resected lymph nodes, hospital stay, and recurrence. Descriptive statistics was used, and Kaplan-Meier curves were calculated. In this analysis 38 patients $(71.1 \%$ men), with a median age of 65 years, were operated. The most frequent location was subcardial (50.0 \%). The most frequent type of resection was total gastrectomy $(60.5 \%)$. The median of surgical time, number of resected lymph nodes and hospital stay; was $190 \mathrm{~min}, 32$ and 6 days respectively. MPO was $18.4 \%$. With a median follow-up of 28 months, a recurrence of $44.7 \%$ was verified; and 5-year OS for stages IIIA, IIIB and IV were $53.3 \%, 46.1 \%$ and $20.0 \%$ respectively $(p=0,007)$. The results achieved, in terms of POM and OS series were similar to national and international series in which neoadjuvant therapies have not been applied.

KEY WORDS: "Stomach Neoplasms"[Mesh]) AND "Stomach Neoplasms/surgery"[Mesh]; "Lymph Node Excision"[Mesh]; Gastric Cancers; Surgery, Lymphadenectomy.

\section{INTRODUCTION}

Gastric cancer (GC) causes $8.2 \%$ of oncological deaths $(787,200)$ and $5.7 \%$ of new cases $(969,000)$ worldwide; being more frequent in men than women (Ferlay et al., 2019). After lung cancer, it is the second leading cause of cancer death, over 780,000 deaths per year (Bray et al., 2018). The areas with the highest incidence rates $(>40 / 100,000)$ are East Asia and the Andean regions of South America (Global Burden of Disease Cancer Collaboration et al., 2017).

Despite special protocols for its treatment (Macdonald et al., 2001); GC remains one of the leading causes of cancer death in Chile; with a mortality prediction rate of $17.5 \times 100,000$ inhabitants and $22.5 \times 100,000$ in men (Carioli et al., 2019); constituting one of the most frequent malignant tumors in men. In La Araucanía region, the overall mortality rate reaches $24.8 \times 105$ inhabitants and in men 33.7 x 105 (Tapia et al., 2010). The adjusted rate was estimated at 38.9 and $27.4 \times 100,000$ inhabitants for men and women respectively for the 1990-2010 period; with a marked decline in the last two decades (Itriago et al., 2013). Despite some stabilization in the general mortality rate from GC, the probability of dying from GC in Chile is approximately $3 \%$, which makes this disease a public health problem (Ministerio de Salud, 2016).

In Chile, more than $80 \%$ of cases are advanced GC (AGC). These are lesions that infiltrate beyond the submucosa layer. Therefore, a series of strategies have been developed to optimize diagnostic and therapeutic processes (Calderón et al., 2007; Tapia et al, 2011; Ministerio de Salud, 2016).

Surgery remains the mainstay in the treatment of AGC, because, as well as allowing tumor excision, allow to determine a better staging of the disease; In addition, it

\footnotetext{
${ }^{1}$ Department of Surgery and Center for Morphological and Surgical Studies (CEMyQ), Universidad de La Frontera, Chile.

${ }^{2}$ Clínica RedSalud Mayor, Temuco, Chile.

${ }^{3}$ Hospital Obrero No1, Caja Nacional de Salud, La Paz, Bolivia.
} 
may be applied as cleaning surgery, for eventual application of adjuvant therapies (Cornejo \& Portanova, 2006; Díaz de Liaño et al., 2008; Ruiz et al., 2009; Degiuli et al., 2016).

The aim of this study was to determine postoperative morbidity (POM) and 5-year overall survival (OS) in patients resected by AGC without neoadjuvant.

\section{MATERIAL AND METHOD}

The report of this study was written based on the MInCir Declaration for the reporting of descriptive observational studies (Manterola \& Astudillo, 2013).

Study design: Case series with follow-up.

Setting: The study was conducted at Clínica RedSalud Mayor Temuco. The recruitment period was between January up was 7 months.

Participants: All patients with AGC consecutively undergoing gastrectomy with extended lymph node dissection (D2), by the first author (CM), were included. Cases of exploratory laparotomy due to disseminated disease, palliative surgeries and those who received additional treatments in addition to surgery were excluded.

Sample size: Since this is an observational and descriptive study, no sample size was estimated. All patients with AGC undergoing D2-gastrectomy in the period and institution indicated were considered.

Variables: The outcome variables were OS and POM. The latter measured up to 30 days after surgery; it was considered dichotomous (present or absent); severity was estimated applying the Clavien proposal (Clavien et al., 2009). Other variables of interest were age, sex, tumor location, stage of the disease (American Joint Committee on Cancer \& American College of Surgeons, 2018), type of surgery, operative mortality and recurrence.

Follow-up protocol: After hospital discharge, all patients were followed up with strict controls at least at months 1 , 2, 3 and 6; and after that once a year. During the controls, a clinical evaluation, general laboratory tests and computed tomography of the abdomen and pelvis were realized. In addition, information on death certificates obtained from the Civil Registry and Identification was used, when necessary. 2008 and December 2019 (12 years). The minimum follow-

Statistical methods: Data collection was carried out and analyzed with the Stata 11.0 / SE® program. Descriptive statistics was used, applying measures of central tendency and dispersion (averages, standard deviations and extreme values). The SV was calculated applying the KaplanMeier method.

Biases: These were reduced with a masked data collection and a complete follow-up of the patients that make up this series for at least 6 months (the last patient recruited).

Ethics: Ethical guidelines for research defined by the Declaration of Helsinki (World Medical Association, 2013), were observed. All patients gave their informed consent in writing.

\section{RESULTS}

During the study period, 38 patients were operated for AGC, with a median age of 65 (34-87) years, $71.1 \%$ of which were male. $78.9 \%$ of the series had some type of comorbidity (Tables I and II).

Table I. Distribution of clinical variables in patients under study. $(\mathrm{N}=38)$

\begin{tabular}{|c|c|c|}
\hline Variable & $\mathrm{N}^{\mathrm{o}}$ cases & $\%$ \\
\hline \multicolumn{3}{|l|}{ Sex } \\
\hline Male & 27 & 71.1 \\
\hline Female & 11 & 28.9 \\
\hline \multicolumn{3}{|l|}{ Comorbidity * } \\
\hline None & 8 & 21.1 \\
\hline AHT & 14 & 36.8 \\
\hline II-DM & 9 & 23.7 \\
\hline $\mathrm{AHT}+\mathrm{II}-\mathrm{DM}$ & 6 & 15.8 \\
\hline Cholelithiasis & 7 & 18.4 \\
\hline Abdominal hernia & 3 & 7.9 \\
\hline \multicolumn{3}{|l|}{ TNM stage } \\
\hline IIIA & 15 & 39.5 \\
\hline IIIB & 13 & 34.2 \\
\hline IV & 10 & 26.3 \\
\hline \multicolumn{3}{|l|}{ Lauren type } \\
\hline Diffuse & 21 & 55.3 \\
\hline Intestinal & 17 & 44.7 \\
\hline \multicolumn{3}{|l|}{ Tumor location } \\
\hline Subcardial & 19 & 50.0 \\
\hline Body & 9 & 23.7 \\
\hline Antrum & 10 & 26.3 \\
\hline \multicolumn{3}{|l|}{ Type of surgery } \\
\hline $\mathrm{D}_{2}$-Total gastrectomy & 23 & 60.5 \\
\hline $\mathrm{D}_{2}$-Subtotal gastrectomy & 15 & 39.5 \\
\hline
\end{tabular}


Table II. Distribution of clinical variables in patients under study. $(\mathrm{N}=38)$

\begin{tabular}{lcc}
\hline Variable & Median & Minimum - Maximum \\
\hline Age (years) & 65 & $34-87$ \\
BMI $\left(\mathrm{kg} / \mathrm{m}^{2}\right)$ & 25,5 & $17-43$ \\
Symptom time (months) & 9 & $2-12$ \\
Surgical time (min) & 190 & $90-225$ \\
Resected lymph nodes $\left(\mathrm{N}^{\circ}\right)$ & 32 & $25-45$ \\
Hospital stay (days) & 6 & $4-9$ \\
Follow-up (months) & 28 & $12-132$ \\
\hline
\end{tabular}

BMI: Body mass index

The most frequent location of the lesions was subcardial $(50.0 \%)$. All cases were stage III or IV according to TNM classification (mainly IIIA, $39.5 \%$ ); and $55.3 \%$ were Lauren's diffuse type. With $100 \%$ resectability of the

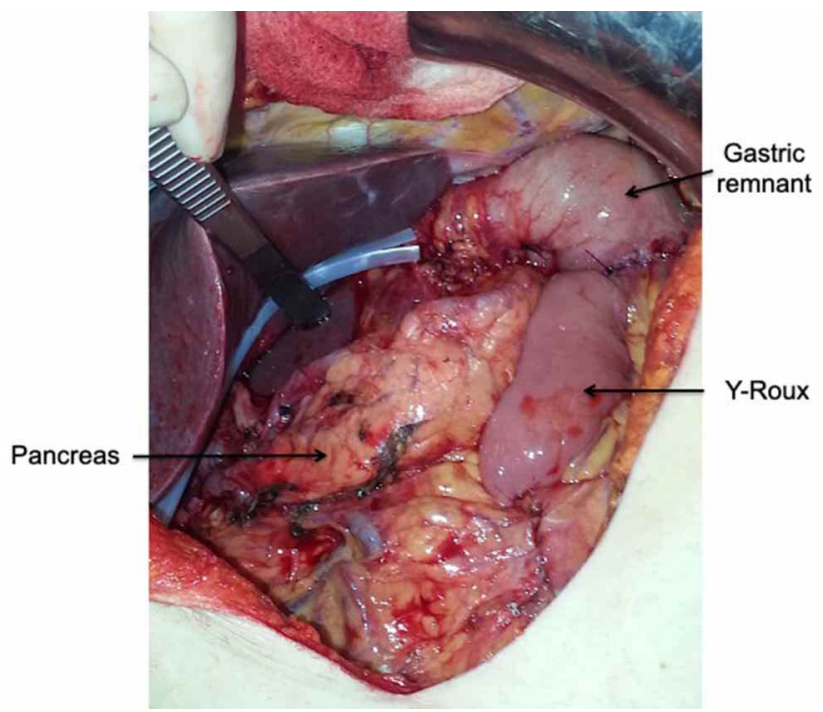

Fig. 1. D2-subtotal gastrectomy. The gastric remnant, the Y-Roux gastrojejunal reconstruction, and pancreas can be observed.

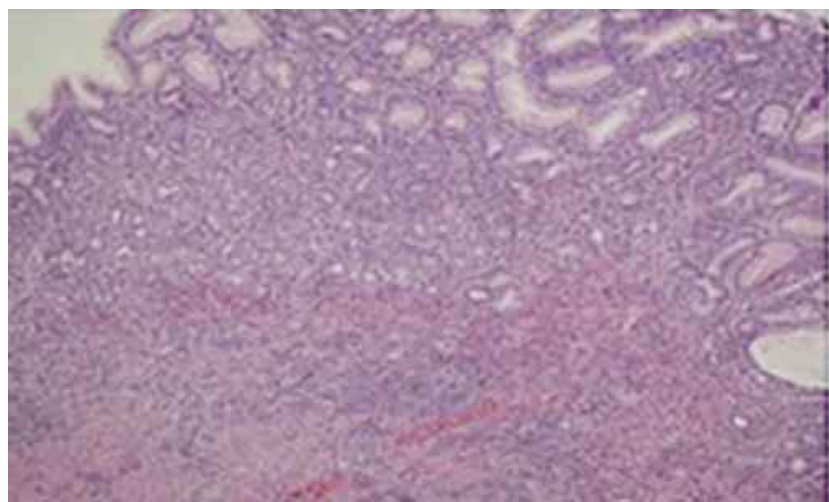

series, the most common type of resection was D2-total gastrectomy (60.5\%) (Table I, Figs. 1 and 2).

The medians of the surgical time, number of resected lymph nodes, and hospital stay were $190 \mathrm{~min}, 32$ y 6 days respectively (Table II).

POM was $18.4 \%$ ( 7 cases), all of which were Clavien \& Dindo type I or II (Table III). There was no operative mortality.

With a median follow-up of 28 months, a recurrence of $44.7 \%$ was verified (Table III). On the other hand, the 5year OS for stages IIIA, IIIB and IV was $53.3 \%, 46.1 \%$ and $20.0 \%(p=0,007)$ respectively (Figs. 3 and 4$)$.

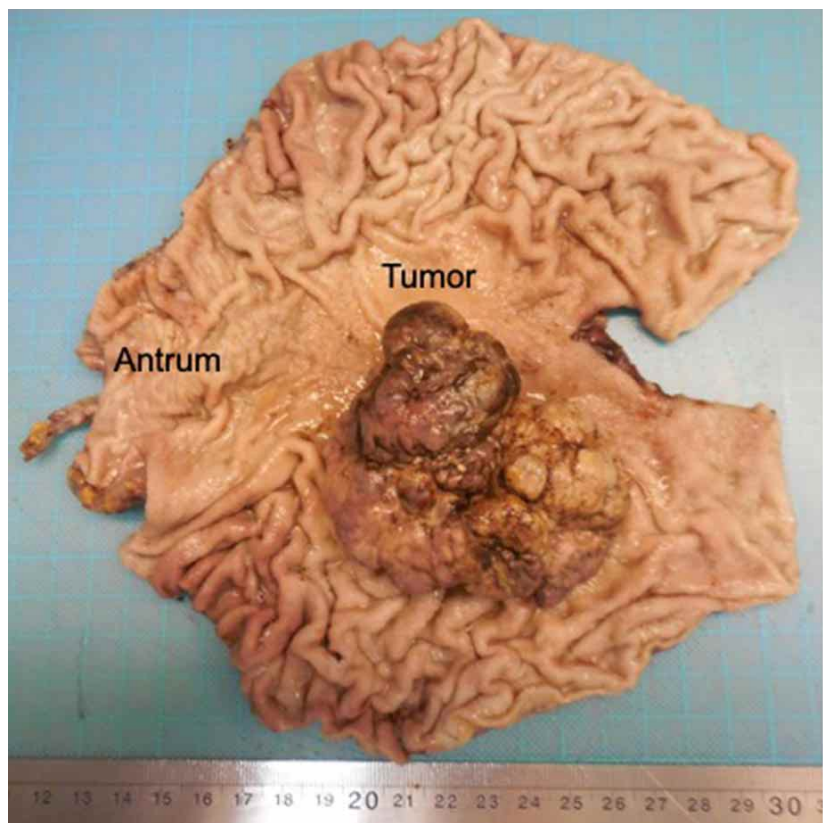

Fig. 2. Surgical specimen of subtotal gastrectomy for AGC. An extensive and proliferative tumor that involves a large part of the gastric body.

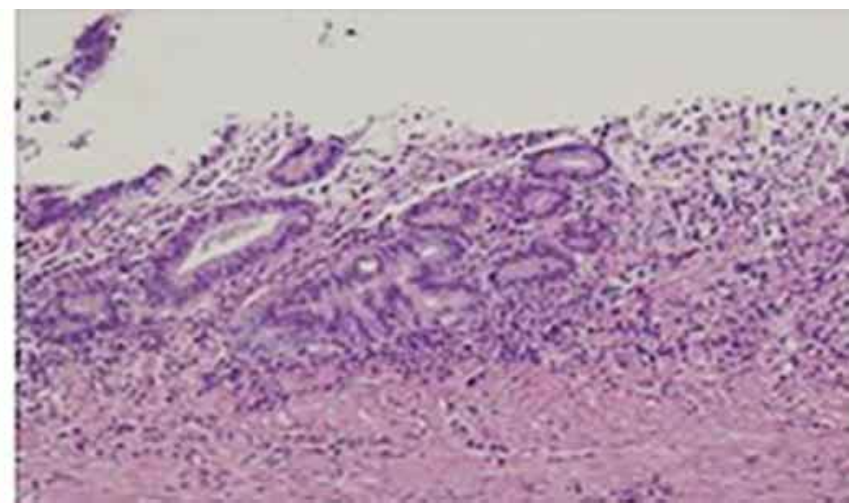

Fig. 3. Microphotographs of a subcardial GC, adenocarcinoma type, well-differentiated tubular. 


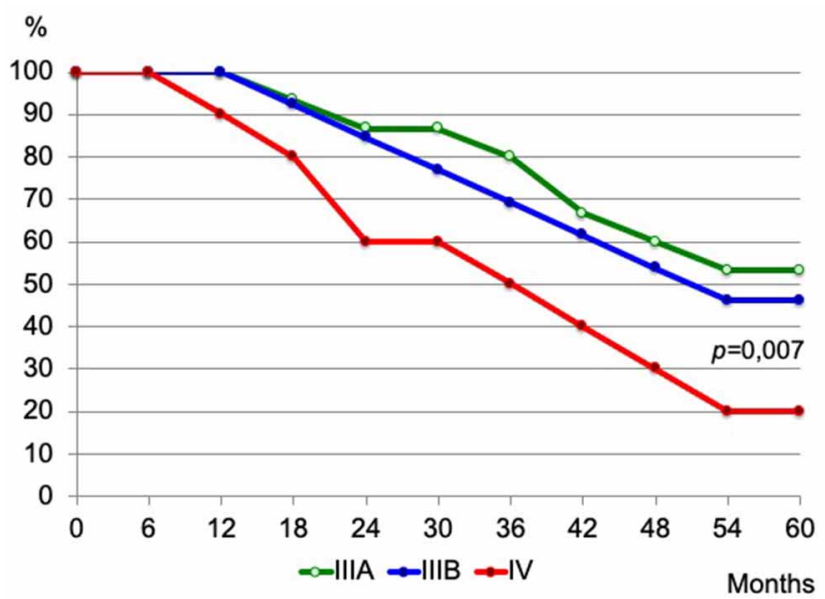

Fig. 4. Actuarial survival curves of the series by stages (IIIA, IIIB and IV).

\section{DISCUSSION}

Novelty of the proposal: The novelty of the proposal is that it is a single-center and regional casuistry of patients of a private health institution; with comparable results with different series from national and international referral centers (Cornejo \& Portanova; Díaz de Liaño et al., 2008, 2009; Ruiz et al.; Tapia et al., 2010, 2011; Valenti et al., 2011; de Steur et al., 2013; Chen et al., 2016; Degiuli et al.; Randle et al., 2016; Tóth et al., 2016; Yang et al., 2016; Bhandare et al., 2017; Uslu et al., 2018; Wang et al., 2018).

Comment on observed results: Surgery is essential in the treatment of GC and is considered curative when all macroscopic disease is removed, followed by the histological demonstration of the absence of neoplasia on the margins of the surgical specimen. Thus, $\mathrm{R} 0$ resection will be considered when in-block excision of the tumor with disease-free histological margins was performed (Bhandare et al.; Uslu et al.; Wang et al.).

Non-Communicable Disease is a denominator used by WHO for oncological diseases (Porta, 2014). It represents a public health problem and will have a sustained increase over time. So, it is projected that by 2030 , they will account for almost $70 \%$ of the total deaths in the world (WHO, 2004).

Thus, GC is responsible for the loss of 15 million years of healthy life (DALYs); either due to premature death or disability (Salomon, 2010).

In relation to the burden of cancer disease, oncological diseases ranked 7 th in importance of DALYs in 2004; which translated into an immense 221,529 years of
Table III. Postoperative morbidity in patients under study.

\begin{tabular}{lcc}
$(\mathrm{N}=38)$ & & \\
\hline Variable & $\mathrm{N}^{\circ}$ cases & $\%$ \\
\hline POM & 7 & 18.4 \\
$\quad$ Present & 31 & 81.6 \\
$\quad$ Absent & & \\
POM etiology & 4 & 10.5 \\
$\quad$ Seroma & 2 & 5.3 \\
$\quad$ Surgical site infection & 1 & 2.6 \\
$\quad$ Intra-abdominal collection & & \\
POM according Clavien & 5 & 13.1 \\
I & 2 & 5.3 \\
II & & \\
Recurrence & 17 & 44.7 \\
$\quad$ Yes & 21 & 55.3 \\
$\quad$ No &
\end{tabular}

POM: Postoperative morbidity life loss, affecting $6 \%$ of the total DALYs of the population, ranking first in men (followed by prostate and lung cancer), and fourth in women (after cancers of the breast, gallbladder, and uterine cervix) (Ministerio de Salud, 2008).

The 5-year OS observed in this study, in the 3 stages measured, is similar to that reported in other series in which only patients with AGC treated with protocols that did not consider neoadjuvant were included (Al-Moundhri et al., 2006; Alici et al., 2006; Garrido et al., 2007; Bhandare et al.; Uslu et al.; Wang et al.). Applying the surgery and adjuvant therapy modality is due to the strong evidence regarding the inappropriate internal and external validity of the Macdonald protocol (Manterola et al., 2006), used as a national protocol for treating GC in our country (Macdonald et al.); that it has only undergone cosmetic modifications by Ministerio de Salud in its application in the last 15 years.

Limitations of the study: Among the limitations, it should be noted that this is a small series, in which all patients underwent surgery by the same surgeon. On the other hand, in the last cases, the follow-up is brief.

\section{CONCLUSIONS}

By way of conclusion, it can be stated that the results verified in this series, in terms of POM, mortality and 5year OS in patients with AGC, are comparable to national and international series in which neoadjuvant therapies have not been applied. 
MANTEROLA, C. \& CLAROS, N. Resultados del tratamiento quirúrgico del cáncer gástrico avanzado. Serie de casos con seguimiento. Int. J. Morphol., 38(5):1479-1484, 2020.

RESUMEN: El cáncer gástrico (CG) es la segunda causa de muerte por cáncer. La mejor opción terapéutica para pacientes con CG avanzado (CGA), sigue siendo la cirugía, que supone la realización de gastrectomía asociada a linfadenectomía D2 (LD2). El objetivo de este estudio fue determinar morbilidad postoperatoria (MPO) y supervivencia (SV) en pacientes resecados por CGA sin neoadyuvancia. Serie de casos con seguimiento, de pacientes con CGA sometidos a gastrectomía total o subtotal con LD2, de forma consecutiva, en Clínica RedSalud Mayor Temuco, entre 2008 y 2019. Las variables resultado fueron MPO y SV actuarial global (SVAG) a 5 años. Otras variables de interés fueron: tiempo quirúrgico, número de linfonodos resecados, estancia hospitalaria y recurrencia. Se utilizó estadística descriptiva, con medidas de tendencia central y dispersión; y análisis de SV con curvas de Kaplan Meier. Se intervinieron 38 pacientes (71,1\% hombres), con una mediana de edad de 65 años. La localización más frecuente fue subcardial $(50,0 \%)$; el tipo de resección más frecuente fue gastrectomía total $(60,5 \%)$. Las medianas del tiempo quirúrgico, del número de linfonodos resecados y de estancia hospitalaria; fue $190 \mathrm{~min}, 32$ y 6 días respectivamente. La MPO fue 18,4\%. Con una mediana de seguimiento de 28 meses, se verificó recurrencia de 44,7 \%; y SVAG a 5 años para estadios IIIA, IIIB y IV de 53,3 $\%, 46,1 \%$ y $20,0 \%$ respectivamente $(\mathrm{p}=0,007)$. Los resultados obtenidos, en términos de MPO, mortalidad y SVAG, fueron similares a series de centros de derivación nacionales e internacionales en los que no se ha aplicado terapias neoadyuvantes.

PALABRAS CLAVE: Cáncer gástrico; Cirugía; Linfadenectomía.

\section{REFERENCIAS BIBLIOGRÁFICAS}

Al-Moundhri, M. S.; Al-Bahrani, B.; Burney, I. A.; Nirmala, V.; AlMadhani, A.; Al-Mawaly, K.; Al-Nabhani, M.; Thomas, V.; Ganguly, S. S. \& Grant, C. S. The prognostic determinants of gastric cancer treatment outcome in Omani Arab patients. Oncology, 70(2):90-6, 2006.

Alici, S.; Kaya, S.; Izmirli, M.; Tuncer, I.; Dogan, E.; Ozbek, H. \& Sayarlioglu, H. Analysis of survival factors in patients with advancedstage gastric adenocarcinoma. Med. Sci. Monit., 12(5):CR221-9, 2006.

American Joint Committee on Cancer \& American College of Surgeons. AJCC Cancer Staging Form Supplement. AJCC Cancer Staging Form Supplement. $8^{\text {th }}$ ed. Chicago, American Joint Committee on Cancer \& American College of Surgeons, 2018. Available from: https:// cancerstaging.org/references-tools/deskreferences/Documents/AJCC $\% 20$ Cancer \%20Staging \%20Form \%20Supplement.pdf

Bhandare, M. S.; Kumar, N. A. N.; Batra, S.; Chaudhari, V. \& Shrikhande, S. V. Radical gastrectomy for gastric cancer at Tata Memorial Hospital. Indian J. Cancer, 54(4):605-8, 2017.

Bray, F.; Ferlay, J.; Soerjomataram, I.; Siegel, R. L.; Torre, L. A. \& Jemal, A. Global cancer statistics 2018: GLOBOCAN estimates of incidence and mortality worldwide for 36 cancers in 185 countries. CA Cancer J. Clin., 68(6):394-424, 2018.
Calderón, G. M. E.; Csendes, J. A.; Ospina, P. C.; Lara, S. A. \& Hodgson, O. F. Evolución del cáncer gástrico en 30 años 1975-2005. Rev. Chil. Cir., 59(5):366-9, 2007.

Carioli, G.; Bertuccio, P.; Malvezzi, M.; Rodriguez, T.; Levi, F.; Boffetta, P.; La Vecchia, C. \& Negri, E. Cancer mortality predictions for 2019 in Latin America. Int. J. Cancer., 147(3):610-32, 2019.

Chen, F. F.; Huang, D. D.; Lu, J. X.; Zhou, C. J.; Zhuang, C. L.; Wang, S. L.; Shen, X.; Yu, Z. \& Chen, X. L. Feasibility of total gastrectomy with D2 lymphadenectomy for gastric cancer and predictive factors for its short- and long-term outcomes. J. Gastrointest. Surg., 20(3):521-30, 2016.

Clavien, P. A; Barkun, J.; de Oliveira, M. L.; Vauthey, J. N.; Dindo, D.; Schulick, R. D.; de Santibañes, E.; Pekolj, J.; Slankamenac, K.; Bassi, C.; et al. The Clavien-Dindo classification of surgical complications: five-year experience. Ann. Surg., 250(2):187-96, 2009.

Cornejo, C. \& Portanova, M. Estudio comparativo de disección ganglionar D1 y D2 para el cáncer gástrico avanzado en el Hospital Rebagliati. Rev. Gastroenterol. Perú, 26(4):351-6, 2006.

de Steur, W. O.; Dikken, J. L. \& Hartgrink, H. H. Lymph node dissection in resectable advanced gastric cancer. Dig. Surg., 30(2):96-103, 2013.

Degiuli, M.; De Manzoni, G.; Di Leo, A.; D`Ugo, D.; Galasso, E.; Marrelli, D.; Petrioli, R.; Polom, K.; Roviello, F.; Santullo, F.; et al. Gastric cancer: current status of lymph node dissection. World J. Gastroenterol., 22(10):2875-93, 2016.

Díaz de Liaño, A.; Yárnoz, C.; Aguilar R, Artieda, C. \& Ortiz, H. Morbidity and mortality in gastrectomy with D2 lymphadenectomy in a specialised unit. Cir. Esp., 83(1):18-23, 2008.

Díaz de Liaño, A.; Yárnoz, C.; Artieda, C.; Aguilar, R.; Viana, S.; Artajona, A. \& Ortiz, H. Results of R0 surgery with D2 lymphadenectomy for the treatment of localised gastric cancer. Clin. Transl. Oncol., 11(3):178-82, 2009.

Ferlay, J.; Colombet, M.; Soerjomataram, I.; Mathers, C.; Parkin, D.M.; Piñeros, M.; et al. Estimating the global cancer incidence and mortality in 2018: GLOBOCAN sources and methods. Int. J. Cancer., 144(8):1941-1953, 2019.

Garrido, M.; Melgoza, G.; Galindo, H.; Madrid, J.; Sánchez, C.; Nervi, B.; Alvarez, M. \& Orellana, E. Treatment of advanced gastric cancer wih oxaliplatin plus 5-fluorouracil/leucovorin (FOLFOX-4 chemotherapy). Rev. Med. Chile., 135(11):1380-7, 2007.

Global Burden of Disease Cancer Collaboration; Fitzmaurice, C.; Allen, C.; Barber, R. M.; Barregard, L.; Bhutta, Z. A.; Brenner, H.; Dicker, D. J.; Chimed-Orchir, O.; Dandona, R.; Dandona, L.; et al. Global, Regional, and National Cancer Incidence, Mortality, Years of Life Lost, Years Lived With Disability, and Disability-Adjusted Life-years for 32 Cancer Groups, 1990 to 2015: A Systematic Analysis for the Global Burden of Disease Study. JAMA Oncol., 3(4):524-48, 2017.

Itriago, L.; Silva, N. \& Cortes, G. Cancer en Chile y el mundo: Una mirada epidemiologica, presente y futuro. Rev. Med. Clin. Condes, 24(4):53152, 2013.

Macdonald, J. S.; Smalley, S. R.; Benedetti, J.; Hundahl, S. A.; Estes, N. C.; Stemmermann, G. N.; Haller, D. G.; Ajani, J. A.; Gunderson, L. L.; Jessup, J. M.; et al. Chemoradiotherapy after surgery compared with surgery alone for adenocarcinoma of the stomach of the gastroesophageal junction. N. Engl. J. Med., 345(10):725-30, 2001.

Manterola, C. \& Astudillo, P. Checklist for reporting of descriptive observational studies. MINCIR initiative. Int. J. Morphol., 31(1):11520, 2013.

Manterola, C.; Torres, R.; Burgos, L.; Vial, M. \& Pineda, V. Methodological quality of an article on the treatment of gastric cancer adopted as protocol by some Chilean hospitals. Rev. Med. Chil., 134(7):920-6, 2006.

Ministerio de Salud (MINSAL). Informe Final: Estudio de Carga Enfermedad y Carga Atribuible. Santiago de Chile, Ministerio de Salud, Gobierno de Chile, 2008. Available from: http://www.cienciasdelasalududla.cl/portales/tp76246caadc23/uploadImg/File/Informe-final-cargaEnf-2007.pdf 
Ministerio de Salud (MINSAL). Estrategia Nacional de Cáncer. Santiago de Chile, Ministerio de Salud, Gobierno de Chile, 2016. Available from: https://www.minsal.cl/wp-content/uploads/2016/10/EstrategiaNacional-de-Cancer-version-consulta-publica.pdf

Porta, M. Epidemiology. $6^{\text {th }}$ ed. New York, Oxford University Press, 2014.

Randle, R. W.; Swords, D. S.; Levine, E. A.; Fino, N. F.; Squires, M. H.; Poultsides, G.; Fields, R. C.; Bloomston, M.; Weber, S. M.; Pawlik, T. M.; et al. Optimal extent of lymphadenectomy for gastric adenocarcinoma: A 7-institution study of the U.S. gastric cancer collaborative. J. Surg. Oncol., 113(7):750- 5, 2016.

Ruiz, E.; Sanchez, J.; Celis, J.; Payet, E.; Berrospi, F.; Chavez, I. \& Young, F. Surgical outcome of 801 patients with localized gastric cancer treated with d2 lymphadenectomy. Rev. Gastroenterol. Perú, 29(2):124-31, 2009 .

Salomon, J. A. Nuevos pesos de la discapacidad para la carga mundial de morbilidad. Bol. Org. Mund. Salud, 88:879, 2010. Available from: http://www.who.int/bulletin/volumes/88/12/10-084301/es

Tapia, E. O.; Roa, S. J. C.; Manterola, D. C.; Puga, A. V.; Villaseca, H. M. \& Araya, O. J. C. Factores asociados al pronóstico de pacientes operados por cáncer gástrico avanzado. Rev. Chil. Cir., 63(2):154-61, 2011.

Tapia, E. O.; Roa, S. J. C.; Manterola, D. C.; Villaseca, H. M.; Gutiérrez, M. V.; Flores, O. P.; Araya, O. J. C. \& Guzmán, G. P. Cáncer gástrico en una región de Chile: Comparación de variables clínicas y morfológicas en dos períodos (1986-1995 y 1996-2005). Rev. Chil. Cir., 62(2):125-30, 2010.

Tóth, D.; Plos, J. \& Török, M. Clinical significance of lymphadenectomy in patients with gastric cancer. World J. Gastrointest. Oncol., 8(2):13646, 2016.

Uslu, A.; Zengel, B.; Ilhan, E.; Aykas, A.; S simsek, C.; Üreyen, O.; Duran, A. \& Okut, G. Survival outcomes after D1 and D2 lymphadenectomy with R0 resection in stage II-III gastric cancer: Longitudinal followup in a single center. Turk. J. Surg., 34(2):125-30, 2018.

Valenti, V.; Hernandez-Lizoaín, J. L.; Beorlegui, M. C.; Diaz-Gozalez, J. A.; Regueira, F. M.; Rodriguez, J. J.; Viudez, A.; Sola, I. \& Cienfuegos, J. A. Morbidity, mortality, and pathological response in patients with gastric cancer preoperatively treated with chemotherapy or chemoradiotherapy. J. Surg. Oncol., 104(2):124-9, 2011.

Wang, H.; Guo, W.; Hu, Y.; Mou, T.; Zhao, L.; Chen, H.; Lin, T.; Li, T.; Yu, J.; Liu, H.; et al. Superiority of the 8th edition of the TNM staging system for predicting overall survival in gastric cancer: comparative analysis of the 7 th and 8 th editions in a monoinstitutional cohort. Mol. Clin. Oncol., 9(4):423-31, 2018.

World Health Organizarion (WHO). Causes of Death. In: World Health Organizarion (WHO). The Global Burden of Disease. Geneva, World Health Organizarion, 2004. pp.8-26.

World Medical Association (WMA). WMA Declaration of Helsinki Ethical Principles for Medical Research Involving Human Subjects. Fortaleza, 64 ${ }^{\text {th }}$ WMA General Assembly, 2013. Available from: https:/ /www.wma.net/policies-post/wma-declaration-of-helsinki-ethicalprinciples-for-medical-research-involving-human-subjects

Yang, K.; Choi, Y. Y.; Zhang, W. H.; Chen, X. Z.; Song, M. K.; Lee, J.; Zhang, B.; Chen, Z. X.; Kim, H. I.; Chen, J. P.; et al. Strategies to improve treatment outcome in gastric cancer: a retrospective analysis of patients from two high-volume hospitals in Korea and China. Oncotarget, 7(28):44660-75, 2016.

\author{
Corresponding author: \\ Dr. Carlos Manterola \\ Department of Surgery and CEMyQ \\ Universidad de La Frontera \\ Temuco \\ CHILE
}

Email: carlos.manterola@ufrontera.cl

Received: 21-02-2020

Accepted: 16-04-2020 